\section{Riqueza, pobreza e infância: $o$ reformismo ilustrado português e a utilidade dos expostos}

\author{
Wealth, poverty, and \\ childhood: Portuguese \\ enlightened reforms and \\ the usefulness of unwanted \\ children
}

\section{Renato Franco}

' Professor, Programa de Pós-graduação em História/ Universidade Federal Fluminense.

Niterói - RJ - Brasil

orcid.org/0000-0003-2878-5412

renfranco@gmail.com
FRANCO, Renato. Riqueza, pobreza e infância: o reformismo ilustrado português e a utilidade dos expostos. História, Ciências, Saúde - Manguinhos, Rio de Janeiro, v.26, supl., dez. 2019, p.109-127.

Resumo

Em meados do século XVIII, a associação entre "gente" e "riqueza" reemergiu como uma tópica relevante para a literatura da razão de Estado, em que, por extensão, sedimentou-se um conjunto de controvérsias a respeito das melhores formas de aproveitar os enjeitados como população útil. Tanto na América quanto na Europa, a ênfase em torno da utilidade dos expostos indicava uma inflexão que secundarizou os significados religiosos do auxílio às crianças em favor dos interesses do Estado. Este artigo analisa os sentidos das reformas da assistência aos expostos em um período de aumento global dos índices de abandono e, em simultâneo, de endividamento de boa parte das instituições de acolhimento.

Palavras-chave: enjeitados; razão de Estado; reformismo ilustrado português.

Abstract

In the mid-eighteenth century, the association between "gentry" and "wealth" reemerged as a topic of relevance in the literature of the reason of State, in which, by extension, a number of controversies about the best ways to make use of abandoned children took root. In the Americas, as in Europe, the emphasis on the usefulness of unwanted children indicated a new slant in which the religious significance of caring for children was subordinated to state interests. A discussion is presented of the meanings of the reforms of care for unwanted children at a time of an overall increase in rates of abandonment and, simultaneously, of indebtedness of many of the institutions where they were taken in.

Keywords: unwanted children; reason of State; Portuguese enlightened reforms. 
A usentes na Ásia e na África, os auxílios sistemáticos aos criadores de expostos se tornaram um dever para os habitantes da América na virada do século XVII para o XVIII. Na última década do seiscentos, mesmo nas principais cidades, como era o caso de Olinda, Salvador e Rio de Janeiro, tudo indica que os índices de abandono fossem baixos e as crianças fossem absorvidas por laços comunitários. ${ }^{1}$ Esse cenário mudaria substantivamente nas décadas seguintes: em meados do século XVIII, a Câmara de Olinda havia estabelecido um subsídio regular; a do Rio de Janeiro estava endividada com os criadores, e a de Salvador lutava para se eximir da assistência. ${ }^{2}$ A despeito das resistências iniciais para implantação do auxílio, quando instituído, o modelo pautado pelo financiamento universal de todos os declaradamente "expostos" foi sendo organizado em algumas áreas, ainda que em boa parte das vilas e cidades esse dever tenha sido simplesmente negligenciado.

Dos anos 1740 em diante, o auxílio foi tornado sistemático na região das Minas Gerais, quando surgiram propostas mais radicais de seleção e de restrição dos serviços a determinadas parcelas das comunidades: em Mariana e em Vila Rica, desde o início da década de 1750, tentou-se limitar o número de atendidos tendo por base o grau de miscigenação - "qualidade" - das crianças. As iniciativas que restringiam o auxílio aos que fossem declaradamente "brancos" perderam em todas as instâncias judiciais ainda em fins dos anos 1750, mas, mesmo assim, durante anos, as duas municipalidades propuseram formas de diferenciar os benefícios com base na "qualidade" dos expostos. Mesmo depois de todas as negativas por parte do Conselho Ultramarino, não é possível saber se houve qualquer seleção surda no cotidiano.

Na virada do século XVIII para o XIX, ao arrepio da legislação vigente, a discriminação segundo critérios raciais voltou a ser objetivada na Casa da Roda do Recife por ordem do bispo Azeredo Coutinho, um dos membros da junta governativa que comandava a capitania de Pernambuco. As iniciativas observadas em Minas e em Pernambuco foram seguramente a mais frontal resistência ao modelo universal e anônimo e estiveram presentes em áreas de grande diversidade étnica, como eram os casos das regiões coloniais. Entretanto, convém ainda ressaltar que os descendentes de escravos eram denunciados sem maior embaraço, mantendo a prática como um direito dos juridicamente livres, não necessariamente "brancos" (Franco, 2014, p.129-148; Franco, 2016, p.437-469).

Apesar das queixas de camaristas, o modelo centrado na responsabilidade das câmaras gozava de grande respaldo moral e, em grande medida, era um elemento identitário das várias comunidades portuguesas pelo mundo, sobretudo a partir de meados do século XVII, quando a Câmara de Lisboa foi definitivamente obrigada a custear os expostos da sede do império, sedimentando assim um modelo que se espalhou rapidamente pelos territórios portugueses. A implantação do subsídio regular no Rio de Janeiro, em Mariana, Vila Rica, Recife, por exemplo, deveu-se à atuação de funcionários régios que recém-chegados logo constatavam a ausência desse cuidado institucional (Marcílio, 2006, p.139-163; Venâncio, 1999, p.26-31; Nascimento, 2008, p.106; Franco, 2014, p.121-129). Naturalmente, a assistência aos enjeitados não era um problema de simples solução e não se limitava apenas a fazer cumprir o que determinavam as normativas legais previstas nas ordenações. Desde o século XV, era sabido que o acolhimento de expostos era um potencial sorvedouro de dinheiro, com instituições frequentemente alegando falta de recursos para financiar o 
crescente número de crianças indesejadas (Viazzo, Bortolotto, Zanotto, 2000, p.70-91). A despeito dos muitos exemplos contemporâneos de insolvência das instituições de caridade, no início do século XVIII, o abandono era uma alternativa legítima, e o acolhimento pago era uma realidade em diferentes localidades do império.

Esse modelo centrado no princípio cristão da caridade e no dever moral do rei de zelar pelos enjeitados sofreu uma inflexão substantiva na segunda metade do século XVIII, quando a salvação dos expostos deixou de ser um assunto marcadamente religioso acolher a fim de evitar a morte sem batismo - para se tornar objeto de cálculo da razão de Estado - acolher a fim de aproveitar como mão de obra. A mudança de ênfase não apenas manteve o abandono como uma prática legítima, mas se tornou a pedra de toque que, em última instância, favorecia a difusão da prática. A partir da segunda metade do século, o abandono atingiu índices exponenciais em diferentes partes do Ocidente e foi frequentemente amparado pela ampliação das redes institucionais de auxílio, marcadamente nas regiões católicas, onde se criou uma oferta institucional que, no limite, forjou também um mercado de interessados em se valer dos benefícios disponíveis. ${ }^{3}$ De Lisboa ao Rio de Janeiro, do Porto a Salvador ou Vila Rica, o tema dos expostos movimentou homens de governo no intuito de formular em conjunto estratégias mais eficazes de assistência. Não obstante as diferentes conjunturas que caracterizavam as dinâmicas em cada localidade em que o fenômeno ocorreu, não é possível, para uma análise global das causas do abandono, perder de vista seu aspecto "estruturante", que garantiu o chão cultural comum para que as práticas fossem objetivadas no cotidiano. ${ }^{4}$

Sobretudo na historiografia brasileira, a despeito da grande qualidade dos trabalhos, observa-se uma tendência a regionalizar as causas do enjeitamento, marginalizando os debates que fundamentaram a reorganização dos aparatos de assistência como um todo e outorgaram legitimidade ao fenômeno na Europa ou na América. As conjunturas locais eram, de fato, importantes para a compreensão dos índices, mas não convém negligenciar a (re)organização dos sistemas de auxílio, sob pena de tornar excepcional uma prática relativamente vulgar nas vilas e cidades, a partir da Época Moderna.

Este artigo volta-se para os sentidos compartilhados do abandono de crianças recémnascidas, secundarizando categorias ainda correntes - e pouco úteis - como "condição colonial" à guisa de fator explicativo para uma estruturação sui generis do fenômeno "nacional", responsável, em última instância, por uma realidade atávica de marginalidade dos menores abandonados no Brasil contemporâneo. Seu objetivo é demonstrar como, tanto das regiões coloniais quanto europeias, um debate comum subsidiou a expansão do auxílio institucional, conferindo uma nova base para a legitimidade da prática que reiterou o sistema vigente havia séculos, transferindo, no entanto, para o Estado - e não mais para o monarca - o papel de grande gestor das crianças.

\section{A forma mentis utilitarista}

Na longa duração, o princípio benemerente que fundamentou o acolhimento regular aos enjeitados ganhara novo ímpeto com a centralização dos sistemas de assistência e, por sua vez, foi um importante ponto de apoio das nascentes monarquias nacionais, reforçando 
o caráter identitário e ideológico das noções de caridade que tinham o rei como a figura máxima de piedade (Sá, 1995; Sá, 1997; Abreu, 2014). No caso português, nas Ordenações Manuelinas de 1521 (Ordenações..., 1984) instituiu-se pela primeira vez o princípio geral de auxílio responsabilizando as comunidades locais - por meio de hospitais e câmaras pelo cuidado com as crianças abandonadas até os 7 anos de idade. ${ }^{5}$ À monarquia coube o papel orquestrador, frequentemente concedendo privilégios ocasionais e/ou isenções de impostos às instituições responsáveis, sem, no entanto, envolver-se diretamente com a administração do sistema.

Ainda que a maior parte do financiamento recaísse sobre as comunidades locais, no âmbito europeu como um todo, os expostos não eram um assunto circunscrito ao universo religioso, integrando também as reflexões de natureza política, sobretudo àquela ligada ao governo civil dos "pobres". O dever civil de educar as crianças abandonadas é mencionado na obra de Juan Luis Vives (1493-1540) De subventione pauperum, de 1526, considerado o primeiro tratado moderno sobre assistência (Vives, 2013, p.92-93). Embora os enjeitados fossem uma referência marginal no texto de Giovanni Botero (c.1544-1617), acabaram por integrar o paradigma, vulgarizado nos escritos do pensador italiano, de que uma população numerosa era a maior riqueza dos reinos.

Doravante, a referência ao emprego estratégico de súditos em funções úteis tornou-se um novo tópos do bom governo, de modo a emular valor a grupos previamente "inúteis":

Quem tem abundância de homens tem também abundância de todas aquelas coisas que provêm do engenho e da indústria do homem [...] Seria muito demorado querer falar minuciosamente de todas as coisas que se podem chamar forças de um Príncipe; contentar-me-ei com as principais, que são a gente, muita e valorosa, o dinheiro, os mantimentos, as munições, os cavalos e as armas ofensivas e defensivas (Botero, 1991, p.135, 148).

Uma população numerosa e submetida aos interesses da racionalidade política pode alimentar o Exército, enriquecer o fisco e o comércio. Em 1623, Filipe IV restringiu os estudos de gramática às maiores cidades da monarquia espanhola, proibindo-os nas Casas de Expostos sob a alegação de que essas crianças seriam mais úteis em outras artes, especialmente na Marinha, "pela falta de pilotos que há neste Reino" (Tomo primero..., 1772, p.86-87).

Ainda que não fosse uma posição homogênea, a associação positiva entre riqueza e população conservou surpreendente longevidade durante a Época Moderna, incorporando novos debates, marcadamente os de natureza econômica, sobre a melhor forma de aproveitar a mão de obra para produzir riqueza. Na virada do século XVII para o XVIII, a "aritmética política" do inglês William Petty (1623-1687) exerceria uma importante influência na matematização do pensamento demográfico, de modo a estabelecer métodos que pretendiam direcionar as políticas de Estado. ${ }^{6}$ Assim, no interior do mercantilismo, diferentes proposições disputavam a hegemonia para fazer valer suas respectivas visões de desenvolvimento (Pincus, jan. 2012, p.3-34).

Também em Portugal, a utilidade da população numerosa era um tema que remetia a distintas tradições de pensamento, não obstante houvesse um nítido protagonismo das 
propostas de cunho econômico, divulgadas pelas gerações críticas que ganharam espaço a partir dos anos 1740. No interior da cultura letrada, assistem-se a ênfases a depender das soluções propostas: da metáfora das "sangrias" feitas pelo Santo Ofício ao debate sobre a utilidade dos vadios, vagabundos e ociosos na produção de manufaturas. As diferenças entre autores como dom Luís da Cunha (1662-1749), cardeal da Mota (1685-1747), Alexandre de Gusmão (1695-1753), Sebastião de Carvalho e Melo (1699-1782), entre outros, sinalizavam a relevância, mas sobretudo a heterogeneidade das propostas em disputa desde o fim do primeiro terço do setecentos.

Em 1740, a publicação da segunda edição de Notícias de Portugal (1655), de Manuel Severim de Faria (1584-1655), recobrava uma importante reflexão sobre a "decadência" do império tendo por base o temário das razões para o sucesso e o fracasso das monarquias, cuja matriz imediata era Botero. O texto de Severim de Faria filiava-se ainda a certa interpretação de que o grande número de migrantes para as áreas coloniais era um elemento definidor da "ruína" da península Ibérica, porque os territórios ultramarinos haviam retirado braços potencialmente úteis e industriosos no continente. Lido décadas depois, o diagnóstico sobre o ultramar posto em Notícias de Portugal poderia soar duro, porque naquele momento a América havia se consolidado como fonte da riqueza que possibilitara aos Bragança sair da instabilidade política e financeira de meados do seiscentos.

De todo modo, emular operosidade e aproveitar a população eram dois princípios discutidos com relativa vulgaridade nos tratados de natureza econômica. Em Londres, ainda nos anos 1740, sob o impacto das reflexões econômicas de matriz anglo-saxã, o futuro marquês de Pombal ficou particularmente impressionado com as considerações de Petty, crítico aberto da ociosidade dos setores religiosos e enfático defensor da "utilidade" dos povos (Dias, 1984, p.227; Santos, 2011, p.2797-2805). Uma recuperação circunstanciada das tradições de pensamento em disputa fugiria das pretensões deste texto; contudo, convém ressaltar apenas que, em termos mais amplos, os expostos tornaram-se assunto de Estado, uma discussão que declinava para três debates contíguos e inter-relacionados: o novo papel da polícia e o ideal de civilidade; a economia política e a produção de riquezas; a filantropia e a reforma das instituições de assistência. Em boa medida, esses debates tinham nos expostos um tema ancilar, mas prepararam o terreno para a formulação de leis, especialmente as que tiveram lugar a partir de 1775.

\section{Um desafio global: dívida e expansão}

Na segunda metade do século XVIII, à medida que o aumento de abandonados foi se tornando mais frequente, disseminou-se uma visão catastrófica dos custos que envolviam a assistência às "pobres" crianças. As avaliações de ordem financeira eram acompanhadas de discursos morais, com críticas à crueldade das mães e acusações de laxismo. Esse diagnóstico pouco abonador poderia facilmente se valer das características regionais como forma de particularizar situações que efetivamente se repetiam em diferentes partes do império em particular e do Ocidente como um todo. Na proposta de criação da roda de Salvador, em 1727, o vice-rei, Vasco Fernandes César de Meneses, justificava o grande número de abandonados em virtude do clima que "conduzia muito para a liberdade dos 
homens e para se continuarem nele a repetição dos vícios" (Biblioteca..., 1950, p.134). Era um artifício retórico, mas frequentemente fundamentou interpretações historiográficas que associaram condição colonial, imoralidade e abandono.

A despeito do tom trágico por parte dos administradores, da condenação moral das mães que enjeitavam, do incentivo a denúncias, da intimidação para o pagamento de taxas para financiar o subsídio, o número de enjeitados seguiu crescente, o abandono conservou seu caráter sigiloso, amparado em uma espécie de pacto de silêncio acordado entre os diferentes grupos sociais (Franco, 2014, p.101-110). Nas comunidades que apresentaram índices substantivos de abandonados, o ato de expor o filho era justificado a partir de tópicas comuns aos vários espaços, consagrando o princípio de que o abandono era um recurso mais aceitável que o infanticídio e o aborto. Boa parte do diagnóstico dos males e das prescrições de soluções que se verificaram na segunda metade do setecentos foi modulada por uma retórica que integrara elites e projetos de Estado sob uma perspectiva filantrópica (Duprat, 1993; Procacci, 1993; Cohen, 2010; Abreu, 2013, p.239-283).

Nessa direção, o financiamento de todas as crianças abandonadas tendeu a se sedimentar como um assunto de interesse e empenho da Coroa portuguesa, quando no reinado josefino a interferência nas Misericórdias recompôs a estrutura administrativa e financeira, desequilibrando as prioridades em favor das ações médicas e da reforma social, valorizando, por exemplo, o atendimento hospitalar e o acolhimento dos expostos. Essa ingerência, que teve na Misericórdia de Lisboa um caso paradigmático - a irmandade, entre 1751 e 1812, teve seu provedor diretamente nomeado pela Coroa - deu o timbre das reformas que se organizariam por todo o império, com diferentes graus de sucesso. ${ }^{7}$ Em maio de 1768, a fim de se arrecadarem as rendas "por um modo mais fácil e menos dispendioso", foi extinta a mesa dos Enjeitados, cujas deliberações ficavam doravante submetidas à mesa da Misericórdia (PMM, 2008, p.178-179). Na América portuguesa, não obstante a assistência aos expostos apresentar uma estrutura administrativa menos complexa, com várias localidades limitando-se ao pagamento camarário - ou à desconsideração da norma -, o tema dos expostos também adquiriu um protagonismo que pode ser constatado na documentação administrativa, por exemplo (Marcílio, 2006; Venâncio, 2010).

Especialmente a partir de 1760, com a criação da Intendência de Polícia de Lisboa, na esteira dos debates sobre utilidade da população, o princípio de que os expostos deveriam ser úteis a si e à pátria poderia ser encontrado com relativa facilidade na documentação civil de vilas, arraiais e cidades coloniais. Em 1766, o governador de Minas Gerais, Luís Diogo Lobo da Silva, em uma de suas correspondências à Coroa, lembrava que nas Minas os privilégios dos criadores dos expostos não poderiam ser efetivados porque a milícia ficaria desguarnecida de braços; no entanto, era preciso fazer valer a lei no que dizia respeito à obrigação de órfãos e enjeitados maiores de 12 anos trabalharem, tal como ocorria em Portugal continental. Era fundamental que a mesma lei destruísse "a preocupação que a ociosidade tem introduzido neste país", porque muitos, considerando injurioso o trabalho, viviam vadios, eram um peso à República, por inutilidade, má criação e falta de sujeição em que se achavam (Carta..., 1766). Na missiva, os temas do trabalho, da polícia e da utilidade emergem como tópicas fundamentais para justificar a reforma das práticas vigentes. 
Nas diferentes partes do império, o tom reformista que passou a vigorar nos assuntos de economia e/ou polícia não provocou qualquer alteração na dinâmica do abandono, mas centrou forças nos destinos das crianças maiores de 7 anos, quando cessava o dever institucional das comunidades. No que se refere aos expostos, a legislação pombalina reiterou as estruturas de acolhimento, limitando-se a organizar de modo mais eficaz o auxílio. A grande inflexão do alvará de 31 de janeiro de 1775 alinhava os destinos dos maiores de 7 anos ao debate sobre utilidade e trabalho como solução para "vadiagem" e, para tanto, reduzia o tempo de criação praticado na Misericórdia de Lisboa de 9 para os 7 anos, restaurando o que determinavam as Ordenações, colocando as crianças a cargo exclusivo dos juízes de órfãos. No texto da lei, a indulgência com os maiores de 7 anos era recriminada não apenas por introduzir um problema orçamentário grave, mas por incentivar a ociosidade das crianças. No entanto, dois anos mais tarde, no alvará de 23 jul. 1777, determinou-se que as enjeitadas sem tutores - fora, portanto, de qualquer aparato familiar ou institucional - fossem novamente recolhidas pela Santa Casa, para assim promover o "benefício público, e em especial das miseráveis enjeitadas, que pelo seu sexo, desamparo, e arriscada idade continuarão a perverterem-se, deixando-as viver sem a sujeição que sempre haviam tido à Mesa da Misericórdia" (Pinto, 1828, p.138-139).

A manutenção do modelo de assistência baseado no anonimato e na legitimidade do abandono associada ao estímulo de políticas e de instituições que garantissem a utilidade dos expostos eram uma verdadeira aposta no abandono como forma de assegurar o melhor aproveitamento de uma população considerada "inútil". As críticas ilustradas centravam-se no descompromisso com os maiores de 7 anos, nos vícios introduzidos na administração dos auxílios, na ausência de senso econômico que emulasse utilidade àqueles filhos do Estado. Sobretudo nos anos 1780, adotou-se políticas subsidiárias que favoreciam a ampliação das redes institucionais de acolhimento, reforçando a legitimidade do enjeitamento, desinibindo ainda mais a disseminação da prática e, consequentemente, constrangendo as comunidades a estabelecer algum tipo de auxílio.

Contudo, a manutenção do modelo implicava conseguir novas formas de financiamento diante das altas dos índices de abandonados. Em Lisboa, em março de 1775, foi publicado um edital obrigando a cota de 10 réis a todas as pessoas do patriarcado que recebessem sacramentos e pagassem conhecenças. A soma da "caritativa e urgente obrigação" destinava-se à criação dos expostos da capital, "um encargo comum dos povos em todos os reinos e estados cristãos" (PMM, 2008, p.56-57). Na mesma direção, a Câmara da cidade foi instada a aumentar sua contribuição regular para o pagamento das famílias acolhedoras, e foram estabelecidos emolumentos para a criação dos expostos na Casa de Suplicação (p.13)

Em diferentes espaços, o financiamento se tornava um assunto de primeira grandeza, o que implicava múltiplas formas de arrecadação: em Vila Rica, os anos 1770 representaram outra arrancada no crescimento dos índices e o aumento exponencial das dívidas com os criadores; apenas em 1793 foi estabelecida uma taxa sobre o consumo de cachaça para cobrir parte dos custos com os enjeitados; na capitania das Minas, o financiamento camarário foi iniciado nos mesmos moldes, no último lustro do século XVIII, pela Câmara de Caeté, Sabará e São João del-Rei; ${ }^{8}$ no Rio de Janeiro, a Santa Casa também emitiu constantes pedidos de 
auxílio financeiro ao rei, porque não conseguia custear o volume crescente de expostos. Ainda que boa parte das vilas e arraiais coloniais tenha deliberadamente desconsiderado o dever de pagar pela criação dos enjeitados, no cômputo geral, o financiamento foi objeto de maior consideração sobretudo a partir do último terço do século XVIII, quando, mesmo em câmaras mais modestas, observa-se o empenho de fazer valer a norma prevista nas Ordenações. A manutenção da prática diante de situações-limite, como eram os exemplos de instituições endividadas por todo o império, pode ter sido um fator relevante para o aumento conjuntural dos expostos também nas regiões sem financiamento regular. ${ }^{9}$ Tratava-se de uma ação legítima, cada vez mais vulgar, e cuja dinâmica apresentava alguma autonomia em relação ao pagamento feito pelas instituições locais de assistência.

A despeito do caráter pouco inovador da lei de janeiro de 1775 , nenhuma norma foi tão incisiva na defesa do modelo anônimo e universal quanto a circular de 24 de maio de 1783, em que o intendente de Polícia Diogo Inácio de Pina Manique (1733-1805) ordenava que fossem instituídas rodas de expostos em todas as vilas e cidades do Reino e que, nos concelhos sem rendimentos próprios, fossem canalizados os cabeções das sisas para o financiamento. $\mathrm{O}$ argumento de que os enjeitados eram uma potencial força produtiva que cabia ao Estado cuidar e educar deveria ser concretizado por meio da multiplicação de locais seguros e que garantissem o sigilo do abandono. Progressivamente, mesmo nas áreas em que essa obrigação foi desconsiderada, o acolhimento das crianças foi associado ao dever civil - e não apenas à caridade cristã -, tornando-se, portanto, uma espécie de direito, guarnecido por uma legislação permissiva. Nos anos 1780, repetiam-se à exaustão as referências aos expostos como "filhos do Estado", "filhos da Pátria". ${ }^{10}$

Na sede do império, a circular do intendente de Polícia foi seguida de mais uma negociação sobre o financiamento dos expostos: em novembro de 1783, a pedido da Misericórdia de Lisboa, a terça parte de uma loteria foi regulamentada para financiar os enjeitados (PMM, 2008, p.204-205). Do outro lado do Atlântico, dez anos antes, em 1773, os irmãos da Santa Casa de Misericórdia do Rio de Janeiro enviaram uma queixosa carta ao rei alegando ter um baixo patrimônio para atender o grande número de enjeitados. Na missiva, recuperava-se a memória da instituição criada em 1738 de modo a exaltar o caráter piedoso que lhe dera origem e, ao mesmo tempo, exacerbar a ruína em que se encontrava, cumprindo uma espécie de retórica comum às demandas relacionadas à caridade. Criada por um devoto "por especial toque da mão de Deus", o rendimento da "tão grande obra pia" era pequeno para a despesa, por isso "prostrados apresentam esta justa súplica esperando que para uma obra tanto do agrado de Deus como da utilidade para Vossa Majestade seja servido determinar alguma consignação para não chegar a diminuir-se o formal edifício da referida caridade" (Requerimento..., 1773).

Depois da vitória conseguida pela Misericórdia de Lisboa contra a Câmara local, um alvará régio de 1778 ordenou que a municipalidade carioca também aumentasse a verba para o subsídio dos expostos, dobrando o valor estabelecido três décadas antes (Cópia..., s.d.). Dois anos mais tarde, a Santa Casa tornou a reclamar dos custos, afirmando não ter rendas específicas para o atendimento: a Câmara, obrigada a subsidiar os novos valores, fizera apenas um pagamento de 200 mil réis, ou seja, 25\% do devido a cada ano. Essa demora comprometia a execução dos sufrágios e do atendimento no hospital; em 1780, a 
irmandade tinha uma dívida de quase sete contos de réis nos pagamentos das amas, quando começou a quitar os valores devidos (Requerimento..., 1780).

No entanto, o avanço das taxas foi significativo a partir de então, agravando as despesas e abrindo espaço para a desorganização e a falta de controle sobre os criadores. Em 1793, a Misericórdia do Rio alegava não ter verbas para pagar as amas, e as crianças não tinham vestuário e tampouco educação na idade competente "para serem úteis ao Estado por uma regra de polícia bem acordada e seguida no corpo das sociedades mais civilizadas" (Cartas..., s.d., f.44.) Por isso, solicitaram, sem sucesso, tal como havia sido concedido a Lisboa, que os párocos cobrassem 10 réis a cada pessoa durante a desobriga, além de requerer a quantia de 480 réis a cada petição de agravo feita na Casa de Suplicação e 1/3 do valor cobrado nas assinaturas dos processos jurídicos para a criação dos expostos. ${ }^{11}$

Não obstante o endividamento crônico observado em diferentes localidades, a ampliação do número de rodas seguiu adiante. Junto às reflexões de fundo econômico, que centravam forças na utilidade e no trabalho da potencial mão de obra, valores como "civilidade", "humanidade", "filantropia" e "razão" foram cada vez mais reivindicados nas correspondências de forma a compor um receituário de justificativas para a expansão do modelo pautado nas rodas e no abandono. Assim, enquanto a ausência de acolhimento institucional impunha um destino "bárbaro" aos expostos, o estabelecimento de rodas atrelava-se à civilização e ao progresso. Em 1779, foi enviada a Lisboa uma representação da Misericórdia de Olinda solicitando alguma verba para subsidiar os expostos da cidade. O texto ressaltava o desejo de socorrer a "humanidade" e a "inocência" dos abandonados da Capitania que até aquela altura estavam sem uma roda dos expostos. ${ }^{12}$

O texto ressaltava o desejo de socorrer a "humanidade" e a "inocência" dos expostos da capitania que até aquela altura estavam sem uma roda,

em que se recebam estes miseráveis inocentes, que, pela não haver, são muitas vezes devorados pelos animais nas ruas públicas onde se lançam; e sem abrigo nem amparo pela maior parte falecem podendo-se criar tantos indivíduos, vassalos de Vossa Majestade, que algum dia com as armas sustentarão o império Lusitano, serão profícuos ao Estado nas Letras, na Agricultura e no Comércio (Carta..., 1779).

Embora não seja possível saber o grau de veracidade dos relatos, a imagem de crianças recém-nascidas devoradas por animais era recorrente, remetendo a uma espécie de paradigma da barbaridade comunitária diante da insensatez pessoal das mães que abandonavam seus filhos. Pouco tempo depois de Olinda, em 1786, foi a vez de o bispo recém-chegado a Pernambuco apelar para a falta de "humanidade" da população, sendo fácil encontrar crianças devoradas por animais porque não havia roda dos expostos. ${ }^{13}$

Nos anos 1780, a aposta no modelo das rodas como forma eficaz de aproveitar a vida dos abandonados foi integrada a novas instituições educativas, criadas sob o ímpeto dos debates sobre polícia e economia que movimentaram os circuitos intelectuais portugueses. Da pena de Pina Manique, designado para o cargo de intendente-geral de Polícia em 1780, fora iniciada, a partir de Lisboa, uma verdadeira onda de reformas que, em seguida, foi estendida a todo o país a fim de aplacar o problema da pobreza por meio da criação de casas de trabalho forçado, de estabelecimentos voltados para a profissionalização de crianças e 
adultos, além de iniciativas que almejavam reformar os costumes dos súditos, como eram o incentivo ao matrimônio, a repressão à prostituição, por exemplo (Abreu, 2013).

Essas políticas tiveram uma institucionalização efetiva em Portugal continental especialmente em Lisboa -, mas não foram totalmente desconsideradas na América. Dos dois lados do Atlântico, com empreendimentos de variados graus de sucesso, o problema dos expostos assumia um protagonismo invulgar diante das demais políticas assistenciais, conjugando crescentes somas de dinheiro e desastrosos índices de mortalidade infantil; calculava-se que, em 1790, a Misericórdia de Lisboa tinha sob sua responsabilidade mais de dez mil crianças (Abreu, 2013, p.239). Foi a partir do que se constatava nas maiores cidades que o drama dos expostos encabeçou - diga-se, por boa parte da Europa - pesquisas sobre as melhores formas de amamentação, os meios de diminuir a mortalidade infantil, as maneiras de adequar os espaços físicos a condições aceitáveis de salubridade etc. Na América portuguesa, os índices de abandono nas regiões urbanas também seguiam em um crescendo, com taxas que frequentemente excediam a casa dos 15\% dos nascidos livres (Marcílio, 2006). No último quartel do século XVIII, o aumento da prática sinalizava uma possível independência do fenômeno em relação às habituais explicações: sem indícios de crise econômica e/ou epidemias, os expostos continuavam a ser presença fácil nas diferentes localidades do império.

\section{Civilização, economia e filantropia}

A inflação de propostas sobre as melhores formas de contornar o desperdício de crianças mortas pela falta de rodas e/ou a desorganização estrutural do aparato assistencial português entrou para o debate público sobretudo a partir dos anos 1780, embora não se possa dizer que essa temática estivesse completamente ausente nas gerações anteriores. De fato, emergem de diferentes regiões arbítrios que pretendem reformar o sistema de amas, encontrar soluções para os altos índices de mortalidade, ampliar o número de rodas, redefinir a estrutura das instituições. $\mathrm{O}$ arco de reflexão iniciado na década de 1780 tem outro ponto alto na publicação do alvará régio de 18 de outubro de 1806, destinado às misericórdias de todo o império. No texto, as referências aos enjeitados e aos pobres despontam em clara assimetria em relação aos demais alvos de caridade, dando um relevo específico ao problema das crianças e recomendando a nomeação de um "mordomo dos expostos" que cuidasse dos interesses dos menores. Além disso, exigia-se das misericórdias um mapa regular das crianças acolhidas, das que faleceram e das que estavam em ofícios; recomendava-se, mais uma vez, o controle estrito sobre as amas; reafirmava-se o privilégio secular dos criadores. Em linhas gerais, o texto mantinha a habitual margem de negociação em torno do anonimato dos que abandonavam:

Quando, porém, aconteça o haver um parto secreto e se recorra a pedir socorro ou às justiças, ou ao provedor da Misericórdia, ou ao mordomo dos expostos, serão obrigados a presta-lo, procurando-lhe uma mulher bem morigerada que em segredo assista ao mesmo parto, fazendo conduzir o exposto para a roda ou entregando-o a uma ama que o crie e administrando-lhe todos os socorros e remédios possíveis, sem que se indague a qualidade da pessoa, nem faça ato algum judicial, donde se possa seguir a difamação (PMM, 2008, p.89). 
Efetivamente, há uma tímida tentativa de contenção do abandono, recuperada do texto das Ordenações... (1985, Livro 1, Tit. 73, §4), determinando que as mulheres solteiras conhecidamente grávidas fossem obrigadas a criar o filho, sendo possível, ou, quando fossem descobertos os pais, fossem constrangidos a ressarcir os custos e assumir a responsabilidade pelos menores (PMM, 2008, p.89). Essa era claramente uma cláusula retórica e ineficaz, diante da ubiquidade do abandono e de seu amplo espectro social; em suma, tratava-se de uma prática comum a diferentes segmentos, utilizada com regularidade e amparada por um jogo de interpretações em torno dos conceitos de honra e necessidade.

Em março de 1812, Filipe Ferreira de Araújo e Castro (1771-1849) foi encarregado de apresentar um diagnóstico sobre a situação das crianças abandonadas nas províncias do reino de Portugal, o que três anos mais tarde resultou em um projeto sobre a administração dos enjeitados, publicado em Londres, no periódico O Investigador Portuguez em Inglaterra (PMM, 2008, p.642-647). No "Projecto sobre a Administração dos Expostos", a associação entre gente numerosa e riqueza aparece como o argumento central que organizava a defesa da vida em contraponto às altas taxas de mortalidade - estimadas em 75\% - e à ineficácia das instituições educativas para as crianças que sobreviviam. O vínculo entre gente e riqueza pode ser percebido logo nos primeiros parágrafos do projeto, em que a epígrafe pinçada da Bíblia - "A multidão do povo é a glória de um rei; a falta de população é a ruína de um príncipe" 14 - é seguida por uma apologia ao aproveitamento útil dos expostos com base nos interesses nacionais, humanitários e religiosos. ${ }^{15}$

No texto, soluções eficazes para os expostos eram prova de civilização dos Estados, mas também derivavam de um problema objetivo e atual: a perda de grandes contingentes nas guerras napoleônicas. Apesar do longevo sistema de auxílio português, era "forçoso confessar com lástima da humanidade e pesar de uma nação civilizada e cristã que a administração deste ramo de serviço público é assaz defeituosa e a educação dos expostos é pela maior parte desprezada" (PMM, 2008, p.643). Meses depois, em 22 de junho de 1812, a Santa Casa de Misericórdia de Lisboa promoveu um congresso de professores de medicina para, entre outros assuntos, discutir meios mais eficazes de reduzir os altos índices de mortalidade na Casa dos Expostos.

Naquele mesmo ano, o médico José Pinheiro de Freitas Soares (1815, p.278-335) escreveu uma memória sobre as vantagens do aleitamento animal, que seria publicada em 1815 nas Memórias econômicas da Academia Real de Ciências. O texto, veiculado em uma instituição feita para promover o desenvolvimento da agricultura, das artes e da indústria, vinha pontuado de bibliografia médica e de experiências sobre as formas mais efetivas de cuidar dos expostos por toda a Europa. As altas taxas de mortalidade foram cotejadas de modo a avaliar um problema supranacional na segunda metade do século XVIII, o que leva o autor a fazer um questionamento recorrente entre as autoridades civis de várias regiões: "Fazendo porém o Estado tão excessivas despesas com as crianças expostas sem que delas tire partido para o serviço da Pátria, que meios devemos abraçar para a segurança de suas vidas?" (p.328-329).

A proposta de reestruturação do atendimento das amas, com preferência pelo aleitamento externo, feito por amas residentes próximas às grandes cidades, mantém intacto o abandono 
como recurso legítimo. No capítulo final, "Arbítrio a benefício da vida dos expostos", sentenciava-se:

É para desejar que o nosso vigilante e iluminado governo faça abraçar estas medidas em todas as cidades e vilas do Reino, aonde houver semelhantes estabelecimentos de humanidade; fazendo também criar nas pequenas povoações um maior número de rodas de expostos, nas quais se recebam as crianças, sem que jamais se consinta que estas crianças sejam conduzidas, como eu tenho observado, às grandes Casas dos Expostos (Soares, 1815, p.328-329).

No início do século XIX, essas e muitas outras tentativas de garantir maior eficácia a partir da reestruturação organizacional expunham a constatação do parcial fracasso das políticas iniciadas a partir da década de 1780. Impossibilitados de obrigar as câmaras de disporem das rendas das sisas, e tampouco interferir nos orçamentos das misericórdias, as deliberações legais sobre os expostos tinham um efeito casuístico, com resultados irregulares a depender da boa vontade daqueles que geriam as câmaras e as misericórdias locais. Por isso, o projeto de Araújo e Castro recomendava a criação de uma autoridade central que fosse capaz de fiscalizar todo o sistema, obrigando as instituições responsáveis a se submeterem a uma jurisdição específica e interventiva (PMM, 2008, p.642-647).

Em 1819, quando o jurista António Gouveia Pinto reuniu a legislação portuguesa, cotejando-a com vários decretos e leis de outras partes e temporalidades, seu intuito era justamente manter intacto o modelo luso. A referência direta ao malogrado arbítrio proposto por Araújo e Castro sete anos antes veio acompanhada de uma crítica aberta à ideia de reforma geral do sistema: "Talvez que por muito pomposo e complicado não obtivesse até agora a régia aprovação, pois é mui certo que é mais fácil emendar alguns defeitos na administração pública, que fazer reformas gerais, cujos resultados não são sempre bons" (PMM, 2008, p.648). Segundo Gouveia Pinto, era preciso apenas fazer cumprir as leis, muitas vezes degeneradas por práticas viciosas: “A nossa legislação é sábia e providente, e que se há algum defeito, é na falta da sua devida execução" (PMM, 2008, p.648).

Essa foi, de fato, a alternativa que se firmou tanto em Portugal quanto no Brasil pós-independência: nenhuma alteração substantiva pôs em questão o anonimato do abandono. Na lei dos municípios de outubro de 1828, a responsabilidade institucional sobre os expostos continuou local, podendo ser dividida entre câmaras e hospitais. O poder central permaneceu como o mentor de políticas públicas, concedendo isenções tributárias esporádicas, não obstante o maior peso financeiro permanecer sobre as comunidades. Tratava-se de um modelo diretamente tributário da organização prescrita nas Ordenações Manuelinas (1984).

\section{Considerações finais}

Abandonar filhos recém-nascidos foi um recurso relativamente comum ao longo de toda a Época Moderna, presente em vilas e cidades, de diferentes partes do Ocidente. Tratava-se de uma prática semelhante, com problemas e soluções próximos, e, portanto, facilmente reconhecível a habitantes de diferentes partes da Europa ou da América. As 
taxas poderiam variar conforme a dinâmica demográfica ou mesmo a capacidade financeira das comunidades, mas não há dúvidas sobre a complexidade do fenômeno, cujas causas objetivas são sempre explicações parciais e inexatas.

De uma perspectiva puramente formal, estabeleceu-se um tópos explicativo das motivações do abandono, sempre associado a situações-limite que exigiam dos cristãos uma contrapartida de misericórdia: diante da pobreza, da libertinagem ou da preservação da honra das mulheres, as repúblicas deveriam organizar uma resposta caritativa eficaz para acolher esses desvalidos. Esse era um raciocínio recorrente que, por consequência, tendia a ver com menos rigor o ato de abandonar do que o de propriamente matar a criança ou abortar o feto. Assim, ao lado de explicações que repetiam o mesmo rol de causas, utilizado à exaustão na literatura moral, desenvolveu-se uma assistência institucional em que o anonimato dos que abandonavam era um direito inegociável.

O modelo organizado a partir do financiamento das comunidades e do segredo como estruturante passou por uma mudança de sentido na esteira da valorização da mão de obra como fator determinante para a produção de riquezas. Efetivamente, as reflexões da economia política ilustrada sobre o caráter estratégico das populações eram mais pragmáticas que as intuições de Botero. Em meados do século XVIII, sedimentou-se, a partir de uma literatura compósita, uma virada substantiva que tendeu a valorizar o Estado como o grande responsável por salvar as vidas da população potencialmente útil.

Ainda que o financiamento permanecesse um assunto sobretudo local, a preocupação com o destino dos expostos passou a integrar um repertório de medidas que pretendeu reformar as políticas públicas para produzir riquezas e também para "policiar" os costumes da população "pobre", um adjetivo impreciso e multidimensional que progressivamente assumia uma conotação "sociológica". Se a legislação pombalina interferiu pouco na dinâmica do enjeitamento, as iniciativas postas em ação a partir de 1780 anunciavam uma verdadeira aposta pelo abandono que certamente contribuiu para o aumento do número de crianças enjeitadas, tamanha a legitimidade da prática não obstante os inúmeros indícios de bancarrota financeira que diferentes instituições de acolhimento anunciavam. Naturalmente, a ruína também era uma tópica discursiva utilizada com frequência para valorizar a situação-limite das instituições de caridade, mas restam poucas dúvidas sobre o alto custo das iniciativas que viram no abandono em massa uma solução plausível. A aposta feita nos anos 1780 não demoraria a dar sinais de exaustão, diante do aumento exponencial dos índices e da dificuldade de financiar tamanha despesa.

De todo modo, vulgarizaram-se por todo o império as controvérsias em torno da utilidade das populações, do dever de aproveitar a mão de obra secularmente desperdiçada, da necessidade de policiar e medicalizar. Encontrar formas mais eficazes de cuidar dos expostos foi uma tônica e, em diferentes regiões, assumiu um protagonismo inédito no debate político: em 1794, por exemplo, Carlos IV lançou uma cédula, válida em todo o império espanhol, equiparando os expostos - "filhos do rei" - aos legítimos, tornando proscrita toda a legislação precedente. No texto, lamentava-se o indecoroso estado dos enjeitados, negligenciados pelas amas e pelas famílias, necessitados da compaixão paternal do monarca (Milton, 2007, p.141-148). Apesar de a legislação espanhola ser anterior, no direito português, a condição de legitimidade dos expostos seria reafirmada pelos tratados 
produzidos por Antônio Gouveia Pinto (1820 e 1828), diretamente influenciado pelo jurista francês Jean-Simon Loiseau (1776-1822) que publicara, em 1811, seu Traité des enfants naturels, adultérins, incestueux et abandonnés (Loiseau, 1811; Sá, 1995, p.96).

Na América portuguesa, a segunda metade do século XVIII foi também um momento de aumento dos índices e da malha assistencial, calcado nos princípios comuns que orientavam as reformas nos dois lados do Atlântico. A inflexão "colonial" não podia ser localizada na multiplicação de instituições específicas, como as Casas pias ou mesmo no aumento substantivo de rodas, mas estava seguramente presente no esforço de direcionar os destinos dos "miseráveis" enjeitados. Esse era um problema comum, debatido com notável sincronia, e que reforçou o modelo institucional que seria repensado, no Brasil, apenas na segunda metade do século XIX, quando o abandono foi se tornando um fenômeno mais localizado entre os financeiramente pobres.

\section{AGRADECIMENTOS}

Esta pesquisa integra um projeto mais amplo, "Governar a miséria: pobreza e marginalidade na América portuguesa (c.1700-1808)", desenvolvido por meio de uma bolsa PNAP-R (Edital 2015), da Biblioteca Nacional do Rio de Janeiro. Agradeço a leitura e as sugestões de Gisele Sanglard, Jonathan Fachini e Renilda Barreto.

\section{NOTAS}

${ }^{1}$ Ainda no século XVII, há uma referência a uma roda que teria existido em Pernambuco, que, se houver existido, durou pouco tempo (Costa, 1984, p.91). Para uma síntese sobre o abandono de crianças no Brasil, ver Marcílio (2006).

2 Para o Rio de Janeiro, ver: Consulta..., 1693.; Consulta..., 1729; Carta..., 1733; Provisão..., 1735; Requerimento..., 1740; Carta..., 1749; Representação..., 1924, p.27. Para a Bahia, ver: Consulta..., 1727; Carta..., 1726; Consulta..., 1734; Carta..., 1734; Carta..., 1736. Para Pernambuco, ver: Carta..., 1744; Carta..., 1746; Carta..., 1730; Carta..., 1732.

${ }^{3}$ Para uma síntese recente sobre o caso europeu, ver: Roman (2018). Ver ainda: Bardet (1991); Sá (1995). Para a relação entre oferta institucional e aumento da demanda por serviços assistenciais nos séculos XVIII e XIX, ver Hunecke (1985, p.3-29).

${ }^{4} \mathrm{O}$ aspecto estrutural do fenômeno é trabalhado em profundidade por Sá (1995).

${ }^{5}$ A responsabilidade legal pelas crianças até os 7 anos de idade é estabelecida em Ordenações Manuelinas (Ordenações..., 1984, Livro I, título 67, parágrafo 10); Ordenações Filipinas (Ordenações..., 1985, Livro 1, título 88, parágrafo 11).

${ }^{6} \mathrm{O}$ termo "aritmética política" tem origem em um tratado iniciado nos anos 1670 e publicado postumamente, em 1690, de autoria de William Petty, que fora secretário pessoal de Thomas Hobbes (1558-1679). Fortemente influenciado pelo método empírico de Bacon (1561-1626), Petty expressava seus argumentos de forma quantitativa, compartilhando a convicção de que a matemática deveria ser a base de todas as ciências racionais de modo a balizar a tomada de decisões de forma precisa. O método indutivo proposto por Bacon presumia a existência de leis naturais que regem o comportamento dos fenômenos naturais e que são acessíveis ao entendimento humano por meio da formulação matemática. Petty situa-se, portanto, entre os primeiros a reivindicar um método científico para analisar fenômenos humanos, cuja orientação fica clara no prefácio de Aritmética política, em que Petty argumenta não ser possível estabelecer análises por meio de "palavras comparativas e superlativas e argumentos intelectuais", por isso, "tratei de (como exemplo da aritmética política que há tempos é meu fito) exprimir-me em termos de número, peso e medida". (Petty, 1983, p.111). A repercussão póstuma do trabalho de Petty seria fundamental para, ao longo do século XVIII, colocar a população como um objeto de conhecimento, suscetível de ser medida e sujeita a regularidades - leis naturais. Ver Pincus (2001, p.272-298); McCormick (2009, p.288).

${ }^{7}$ Para uma análise sobre reformismo ilustrado e assistência em Portugal, ver Lopes (2000, v.1, p.27-423); PMM, (2008, p.7-36); Abreu (2013). 
${ }^{8}$ Embora não haja monografias de fôlego sobre os casos de Caeté e Sabará, no Arquivo Público Mineiro (APM), conservam-se os registros manuscritos das matrículas dos expostos das duas vilas mineiras. Ver, Registro... (s.d.a, s.d.b); para o caso de São João del Rei, ver Brügger (2006, p.116-146).

${ }^{9}$ Mesmo em áreas com diferentes regimes demográficos, o aumento dos expostos apresenta temporalidades próximas. Para uma síntese do fenômeno brasileiro, ver Marcílio (2006). Para o caso do Rio de Janeiro, ver Venâncio (1999, 2002); Franco (2011, p.128-134); para Salvador, ver Venâncio (1999); para Curitiba, ver Cavazzani (2005); para Pernambuco, ver Nascimento (2008); para Mariana, ver Damasceno (2011); para Vila Rica, ver Franco (2014); para o Rio Grande do Sul, ver Silva (2014, 2018); para o Rio Grande do Norte, ver Paula (2016). Para uma reflexão sobre as regiões sem financiamento institucional, ver Venâncio (2010, p.59-80).

${ }^{10}$ A ordem circular de maio de 1783 enquadra-se no que certa historiografia chamou, de modo impreciso, de "mentalidade populacionista": "Sendo o aumento da população um dos objetos mais interessantes e próprios de uma bem regulada Polícia, por consistirem as riquezas de um Estado na multidão de habitantes, se acha este tão esquecido neste Reino, que em algumas terras dele se veem inteiramente fechadas e sem gente uma grande parte das casas, sem haver quem as habite; e sendo a origem, entre outras, de uma tão sensível diminuição os reiterados infanticídios que estão acontecendo todos os dias e em todas as terras em que não há rodas ou berços para enjeitados, que sendo expostos de noite às portas dos particulares, a quem faltam meios ou a vontade para os criar, são sacrificados como inocentes vítimas da indolência com que os povos veem perecer tantos cidadãos que poderiam ser úteis ao Estado e de glória para a Nação" (Pinto, 1828, p.213-216).

${ }^{11}$ Essa solicitação seria concedida em 1815, após a transferência da Corte para o Rio de Janeiro (Solicitação, s.d.).

${ }^{12}$ A roda dos expostos era um mecanismo, em forma de tambor ou portinhola giratória, utilizado para abandonar anonimamente recém-nascidos. Era construída de tal modo que aquele que expunha a criança não era visto por aquele que a recebia. Até o fim do período colonial, era reduzido o número de rodas, e a maior parte dos enjeitados foi abandonada nas portas de casas, ruas, praças e edifícios públicos.

13 "Porém o que mais me enche de horror é o não haver uma roda de expostos, ao mesmo tempo que estas terras ao passo que são mais livres em costumes, vem igualmente em consequência a serem mais fecundas. Encontram-se frequentemente pelas ruas do Recife os porcos com crianças mortas na boca, porque os pais, ou miseráveis, ou desumanos, as expõem em canastra à porta de seus vizinhos, estes pelos mesmos princípios em as achando fazem o mesmo, e assim andam estes infelizes até que por falta de calor e de sustento morrem; os porcos encontrando estas canastras sem defesa as arrombam e se alimentam dos tenros cadáveres que nelas jazem sepultados; estes tristes sucessos ferem o coração dos que os veem de perto e ao longe são bem capazes de excitar por si mesmos a compaixão de um ministro de Estado, tão zeloso do bem público como é Vossa Excelência, para lhe dar uma pronta e eficaz providência e a que pode ter sem lesão da Real Fazenda segundo o meu parecer" (Ofício..., 1786). A referência a porcos que devoravam os recém-nascidos pode ser encontrada também no ofício enviado pelo ouvidor da capitania ao secretário de Estado da Marinha e do Ultramar em Ofício..., 1787.

${ }^{14}$ In multitudine populi dignitas regis, in paucitate plebis ignominia principis. Provérbios de Salomão (A Bíblia..., 1985, 14.28). No Antigo Testamento, a associação entre números de súditos e soberania política é particularmente frequente, reiterando positivamente e em termos amplos o mandato de crescer e multiplicar o gênero humano (Gn 9.7).

${ }^{15}$ No introito do referido projeto, é possível observar, mais uma vez, a associação entre gente e riqueza. "Se o número de homens é o primeiro argumento das forças de uma nação, se a útil aplicação dos seus braços é o princípio fecundo da abundância e prosperidade publica, é evidente que a conservação e aproveitamento de milhares de crianças abandonadas, sendo um objeto recomendável à humanidade, à religião e ao interesse nacional, merece os esforços da virtude e do saber, é digno dos cuidados do governo e da consideração de um soberano que é pai de seus vassalos que entende os seus verdadeiros interesses e identifica a sua glória e felicidade com a ventura do seu povo" (PMM, 2008, p.642).

\section{REFERÊNCIAS}

A BÍBLIA...

A Bíblia de Jerusalém. São Paulo: Edições Paulinas. 1985.
ABREU, Laurinda.

O poder e os pobres: as dinâmicas políticas e sociais da pobreza e da assistência em Portugal (séculos XVI-XVIII). Lisboa: Gradiva. 2014. 
ABREU, Laurinda.

Pina Manique: um reformador no Portugal das Luzes. Lisboa: Gradiva. 2013.

\section{BARDET, Jean-Pierre.}

Enfance abandonnée et société en Europe: XIVeXXe siècle - Actes du colloque international, Rome. Rome: École française de Rome. 1991.

\section{BIBLIOTECA...}

Biblioteca Nacional do Rio de Janeiro (BNRJ). Consultas do Conselho Ultramarino - Bahia. Documentos Históricos, n.90. 1950.

BOTERO, João.

Da razão de Estado. Tradução e notas de Luís Torgal e Rafaella Longobard Ralha. Coimbra: Inic. 1991.

BRÜGGER, Sílvia M.J.

Crianças expostas: um estudo da prática do enjeitamento em São João del Rei, séculos XVIII e XIX. Topoi, v.7, n.12, p.116-146. 2006.

CARTA...

Carta da Mesa da Santa Casa de Misericórdia de Olinda à rainha [dona Maria I] pedindo recursos e a instalação da roda dos expostos na Santa Casa. Pernambuco, cx. 134, doc. 10.081 (Arquivo Histórico Ultramarino, Lisboa). 1779.

CARTA...

Carta de Luis Diogo Lobo da Silva, governador das Minas, para D. José, dando o seu parecer sobre a representação dos oficiais da Câmara de Vila Rica, de 22/11/1759, a respeito das datas e medições das sesmarias, dos salários dos capitães de mato, dos expostos e ainda do começo das caçadas. Minas Gerais, cx. 88, doc. 44 (Arquivo Histórico Ultramarino, Lisboa). 1766.

CARTA...

Carta dos oficiais da Câmara do Rio de Janeiro ao rei d. João V sobre as grandes despesas do senado com as festividades da religião católica e com as principais procissões, solicitando a extinção da obrigação da Câmara com os enjeitados, repassando-a à Santa Casa de Misericórdia. Rio de Janeiro, cx. 42, doc. 4306 (Arquivo Histórico Ultramarino, Lisboa). 1749.

CARTA...

Carta dos oficiais da Câmara de Olinda ao rei [dom João V], sobre suspensão da distribuição em dinheiro para os expostos, a pretensão da Santa Casa da Misericórdia à dita quantia para distribuí-lo, e os motivos da oposição da Câmara. Pernambuco, cx. 63, doc. 5389 (Arquivo Histórico Ultramarino, Lisboa). 1746.

CARTA...

Carta da Mesa da Santa Casa da Misericórdia de Olinda ao rei [dom João V], pedindo que a consignação que a dita Câmara tem para os enjeitados, seja dada à Santa Casa para criação dos mesmos. Pernambuco, cx. 61, doc. 5203 (Arquivo Histórico Ultramarino, Lisboa). 1744.

CARTA...

Carta do [vice-rei e capitão-general do Estado do Brasil] André de Melo e Castro, [conde das Galveias] ao rei [dom João V] comunicando a assistência aos doentes e enjeitados da Misericórdia pelas rendas anuais de duzentos mil reis. Bahia, cx. 56, doc. 4799 (Arquivo Histórico Ultramarino, Lisboa). 1736.

CARTA...

Carta do [vice-rei e capitão-general do estado do Brasil], Vasco Fernandes César de Meneses, conde de Sabugosa ao rei [dom João V] comunicando a assistência aos enjeitados com o rendimento dos açougues ou currais. Bahia, cx. 49, doc. 4360 (Arquivo Histórico Ultramarino, Lisboa). 1734.

CARTA...

Carta dos oficiais da Câmara do Rio de Janeiro ao rei d. João V, remetendo cópias das precatórias requeridas ao provedor da Fazenda Real daquela cidade, Bartolomeu de Serqueira Cordovil, para que conceda das propinas daquele Juízo uma importância em dinheiro para pagar o salário do síndico e do procurador do senado na Corte, devido à pouca receita do Senado, cujas despesas aumentaram com os custos referentes aos enjeitados. Rio de Janeiro, cx. 25, doc. 2695 (Arquivo Histórico Ultramarino, Lisboa). 1733.

CARTA...

Carta dos oficiais da Câmara de Recife ao rei [dom João V], sobre a doação dos rendimentos dos contratos que administrava a dita Câmara para as despesas dos enjeitados e outras do real serviço. Pernambuco, cx. 43, doc. 3862 (Arquivo Histórico Ultramarino, Lisboa). 1732.

\section{CARTA...}

Carta do [governador da capitania de Pernambuco], Duarte Sodré Pereira Tibão, ao rei [dom João V], sobre a representação dos oficiais da Câmara do Recife a respeito do seu patrimônio e das propinas que pendem para as festas reais. Pernambuco, cx. 41, doc. 3671 (Arquivo Histórico Ultramarino, Lisboa). 1730.

CARTA...

Carta (cópia) do [vice-rei e capitão-general do estado do Brasil], conde de Sabugosa, Vasco Fernandes César de Meneses ao rei [dom João V] sobre a necessidade de criar uma roda preta da Santa Casa da Misericórdia da Bahia a fim de atender as várias crianças que ficam expostas a voracidade dos animais. Bahia, cx. 26, doc. 2325 (Arquivo Histórico Ultramarino, Lisboa). 1726. 


\section{CARTAS...}

Cartas e ofícios. Registro de cartas e ofícios (1779-1810), f.44 (Arquivo Histórico da Santa Casa de Misericórdia do Rio de Janeiro, Rio de Janeiro). s.d.

CAVAZZANI, André Luiz M.

Um estudo sobre a exposição e os expostos na Vila da Nossa Senhora da Luz dos Pinhais de Curitiba. Dissertação (Mestrado em História) Universidade Federal do Paraná, Curitiba. 2005.

COHEN, Déborah.

La nature du peuple: les formes de l'imaginaire social (XVIIIe-XXIe siècles). Seyssel: Champ Vallon. 2010.

\section{CONSULTA...}

Consulta do Conselho Ultramarino ao rei D. João V sobre a existência do açougue Misericórdia da Bahia e das despesas dos enjeitados. Bahia, cx. 47, doc. 4199 (Arquivo Histórico Ultramarino, Lisboa). 1734.

\section{CONSULTA...}

Consulta do Conselho Ultramarino acerca de uma provisão ordenado ao governador da Capitania do Rio de Janeiro, Luis Vahia Monteiro, declarasse se seria possível tirar-se a administração dos contratos à Câmara daquela Cidade em todo ou em parte e incorporasse na Fazenda Real. Rio de Janeiro, cx. 27, doc. 6078, Castro Almeida (Arquivo Histórico Ultramarino, Lisboa). 1729.

\section{CONSULTA...}

Consulta do Conselho Ultramarino ao rei d. João V sobre o que o vice-rei e capitão-general do estado do Brasil, conde de Sabugosa, Vasco Fernandes César de Meneses, da conta da roda dos enjeitados que se ergueu na cidade da Bahia. Bahia, cx. 30, doc. 2753 (Arquivo Histórico Ultramarino, Lisboa). 1727.

CONSULTA...

Consulta do Conselho Ultramarino sobre a representação do Provedor e irmãos da Mesa da Misericórdia do Rio de Janeiro em que pediam por esmola um dos ramos das miunças daquela Capitania para ajudar as despesas do seu hospital. Rio de Janeiro, cx. 10, doc. 1880, Castro Almeida (Arquivo Histórico Ultramarino, Lisboa). 1693.

CÓPIA...

Cópia do alvará régio, de 8 de outubro de 1778 . Lata 721-A, Casa dos Expostos, Avulsos (Arquivo Histórico da Santa Casa de Misericórdia do Rio de Janeiro, Rio de Janeiro). s.d.

COSTA, Francisco Augusto Pereira da. Anais Pernambucanos. v.4. Recife: Fundarpe. 1984.
DAMASCENO, Nicole de O.A.

Ser exposto: "a circulação de crianças" no termo de Mariana (1737-1828). Dissertação (Mestrado em História) - Universidade Federal de Ouro Preto, Mariana. 2011.

DIAS, José Sebastião da Silva.

Pombalismo e projecto político. Lisboa: Centro de História da Cultura da Universidade Nova de Lisboa. 1984.

DUPRAT, Catherine.

Pour l'amour de l'humanité: le temps des philanthropes. Paris: Éditions du CTHS. 1993.

FRANCO, Renato.

Discriminação e abandono de recém-nascidos mestiços na América portuguesa: os exemplos de Mariana, Vila Rica e Recife. Varia Historia, v.32, n.59, p.437-469. 2016.

FRANCO, Renato.

A piedade dos outros: o abandono de recémnascidos em uma vila colonial, século XVIII. Rio de Janeiro: FGV. 2014.

FRANCO, Renato.

Pobreza e caridade leiga: as Santas Casas de Misericórdia na América Portuguesa. Tese (Doutorado em História Social) - Universidade de São Paulo, São Paulo. 2011.

HUNECKE, Volker.

Les enfants trouvés: contexte européen et cas milanais (XVIIIe-XIXe siècles). Revue d'Histoire Moderne et Contemporaine, t.32, n.1, p.3-29. 1985.

LOISEAU, Jean-Simon.

Traité des enfants naturels, adultérins, incestueux et abandonnés. Paris: J. Antoine. 1811.

LOPES, Maria Antónia.

Pobreza, assistência e controlo social, Coimbra 1750-1850. Viseu: Palmage Editores. 2v. 2000.

MARCÍLIO, Maria Luíza.

História social da criança abandonada. São Paulo: Hucitec. 2006.

MCCORMICK, Ted.

William Petty: and the ambitions of political arithmetic. New York: Oxford University Press. 2009.

MILTON, Cynthia E.

The many meanings of poverty: colonialism, social compacts, and assistance in eighteenth-century Ecuador. Stanford: Stanford University Press. 2007.

NASCIMENTO, Alcileide Cabral do. A sorte dos enjeitados: o combate ao infanticídio e a institucionalização da assistência às crianças abandonadas no Recife (1789-1832). São Paulo: Annablume. 2008. 
OFÍCIO...

Ofício do ouvidor da capitania de Pernambuco, Antônio Xavier de Moraes Teixeira Homem, ao secretário de estado da Marinha e Ultramar, Martinho de Melo e Castro, informando o estado do prédio atual da Alfândega, da produção do algodão, da necessidade de uma leprosaria, dos esforços da população para se construir uma, e da criação de uma roda dos expostos. Pernambuco, cx. 159, doc. 11475 (Arquivo Histórico Ultramarino, Lisboa). 1787.

\section{OFÍCIO..}

Ofício do Bispo de Pernambuco, frei d. Diogo de Jesus Jardim, ao secretário de estado da Marinha e Ultramar, Martinho de Melo e Castro, sobre a possibilidade de transformar o Colégio dos Jesuítas em um seminário, e sugerindo formas de gestão e a necessidade de prestar socorro para os expostos. Pernambuco, cx. 157, doc. 11321 (Arquivo Histórico Ultramarino, Lisboa). 1786.

\section{ORDENAÇÕES...}

Ordenações Filipinas. Reprodução fac-similar da edição feita por Cândido Mendes de Almeida, Rio de Janeiro, 1870. Lisboa: Fundação Calouste Gulbenkian. 2v. 1985.

ORDENAÇÕES...

Ordenações Manuelinas. Nota de apresentação Mário Julio de Almeida Costa. Lisboa: Fundação Calouste Gulbenkian. 3v. 1984.

PAULA, Thiago do Nascimento Torres de. O abandono de crianças na América ibérica: um estudo sobre os recém-nascidos expostos e suas trajetórias na freguesia da cidade do Natal (Capitania do Rio Grande do Norte, 1727-1835). Tese (Doutorado em História) - Universidade Federal do Paraná, Curitiba. 2016.

PETTY, William.

Petty. Série "Os economistas". São Paulo: Abril Cultural. 1983.

\section{PINCUS, Steve.}

Rethinking mercantilism: political economy, the British empire, and the Atlantic world in the seventeenth and eighteenth centuries. William and Mary Quarterly, 3d series, v.69, n.1, p.3-34. jan. 2012.

PINCUS, Steve.

From holy cause to economic interest: the study of population and the invention of the State. In: Houston, Alan; Pincus, Steve (Ed.). A nation transformed: England after the Restoration. Cambridge: Cambridge University Press. p.272298. 2001.

PINTO, Antônio Joaquim Gouveia. Exame crítico e histórico sobre os direitos estabelecidos pela legislação antiga e moderna, tanto pátria como subsidiária, e das nações mais vizinhas e cultas relativamente aos expostos ou enjeitados. Lisboa: Typographia da Academia Real de Sciências. 1828.

PINTO, Antônio Joaquim Gouveia. Compilação das providências, que a bem da criação, e educação dos expostos ou enjeitados que se tem publicado. Lisboa: Impressão Régia. 1820.

PMM.

Portugaliae monumenta misericordiarum. Sob o signo de mudança: de D. José I a 1834. v.7. Coordenação científica de José Pedro Paiva; Centro de Estudos de História Religiosa. Lisboa: União das Misericórdias Portuguesas. 2008.

PROCACCI, Giovanna.

Gouverner la misère: la question sociale en France, 1789-1848. Paris: Seuil. 1993.

PROVISÃO...

Provisão do rei d. João V concedendo aos oficiais da Câmara do Rio de Janeiro uma quantia em dinheiro para pagar as despesas do senado que aumentaram com a criação da roda dos enjeitados e ordenando que o provedor da Fazenda Real do Rio de Janeiro, Bartolomeu de Sequeira Cordovil, pague pelos sobejos do contrato dos subsídios, as propinas e despesas do senado que ultrapassarem o seu rendimento. Rio de Janeiro, cx. 28, doc. 2956 (Arquivo Histórico Ultramarino, Lisboa). 1735.

REGISTRO...

Registro da matrícula de expostos da Câmara municipal de Caeté. (Arquivo Público Mineiro, Belo Horizonte). s.d.a.

REGISTRO...

Registro da matrícula de expostos da Câmara municipal de Sabará. (Arquivo Público Mineiro, Belo Horizonte). s.d.b.

REPRESENTAÇÃO...

Representação dos oficiais da Câmara do Rio de Janeiro, na qual pedem para passar novamente para a Câmara o rendimento e arrecadação do subsidio pequeno dos vinhos, ou as sobras dos impostos criados para os soldos dos Governadores, para assim poderem concorrer às despezas com os enjeitados. Anais da Biblioteca Nacional, v.46. 1924.

\section{REQUERIMENTO...}

Requerimento do provedor e mais irmãos da Santa Real Casa da Misericórdia do Rio de Janeiro à rainha [D. Maria I], solicitando ajuda de custo para a criação e sustento dos expostos naquela instituição, conforme os benefícios concedidos ao hospital da cidade de Lisboa, visto que desta forma conseguiriam aumentar o pequeno rendimento que possuem para este fim. Rio de Janeiro, cx. 112, doc. 9316 (Arquivo Histórico Ultramarino, Lisboa). 1780. 
REQUERIMENTO...

Requerimento do provedor e mais irmãos da Mesa da Santa Casa de Misericórdia do Rio de Janeiro ao rei [d. José] solicitando alguma consignação para poderem continuar mantendo a roda de expostos daquela Casa, que um devoto havia criado em 1738, e que agora enfrentava grandes dificuldades financeiras, face às outras despesas da Casa com os pobres e doentes. Rio de Janeiro, cx. 96, doc. 8258 (Arquivo Histórico Ultramarino, Lisboa). 1773.

\section{REQUERIMENTO...}

Requerimento de d. Ascensa de Menezes, d. Ana da Fonseca, Nicolau Rodrigues do Luro, d. Bárbara de Barcelos, Helena da Fonseca Vieira, Brites Rangel de Mendonça e outros moradores da cidade do Rio de Janeiro, no qual pedem que das sobras do donativo Real se lhes pagassem diversas quantias em dívida pela criação dos expostos (1740). Rio de Janeiro, cx. 47, doc. 10958, Castro Almeida (Arquivo Histórico Ultramarino, Lisboa). 1740.

ROMAN, Nicoleta (Ed.).

Orphans and abandoned children in European history: sixteenth to twentieth centuries. New York: Routledge. 2018.

SÁ, Isabel dos Guimarães.

Quando o rico se faz pobre: misericórdias, caridade e poder no império português, 1500-1800. Lisboa: Comissão Nacional para as Comemorações dos Descobrimentos Portugueses. 1997.

SÁ, Isabel dos Guimarães. A circulação de crianças na Europa do Sul: o caso dos expostos do Porto no século XVIII. Lisboa: Fundação Calouste Gulbenkian; JNICT. 1995.

SANTOS, Antonio Cesar de Almeida.

Pombal e a política econômica portuguesa na segunda metade do Setecentos. In: Congresso Internacional de História, 4., 2011, Maringá. Anais... Maringá: Universidade Estadual de Maringá. p.2797-2805. 2011.

SILVA, Jonathan Fachini da. A prática da exposição de crianças e o mundo atlântico: Rio Grande de São Pedro, séculos XVIII-XIX. Exame de qualificação (Doutorado em História) - Unisinos, São Leopoldo. 2018.
SILVA, Jonathan Fachini da.

Os filhos do destino - a exposição e os expostos na freguesia de Madre de Deus de Porto Alegre (1772-1837). Dissertação (Mestrado em História) - Unisinos, São Leopoldo. 2014.

SOARES, José Pinheiro de Freitas.

Memória sobre a preferência do leite de vacas ao leite de cabras para o sustento das crianças, principalmente nas grandes Casas dos Expostos; e sobre algumas outras matérias que dizem respeito à criação deles. In: Memórias econômicas da Academia Real das Sciências de Lisboa para o adiantamento da agricultura, das artes, e da indústria em Portugal, e suas conquistas. t.5. Lisboa: Academia Real das Ciências. p.278-335. 1815.

SOLICITAÇÃO.

[Solicitação]. Série Saúde, IS31, Avulsos (Arquivo Nacional do Rio de Janeiro, Rio de Janeiro). s.d.

TOMO PRIMERO...

Tomo Primero de las leyes de recopilacion que contiene los libros primero, segundo, tercero, quarto i quinto. Madrid: En la imprenta de Pedro Marin. 1772.

VENÂNCIO, Renato Pinto (Org.).

Uma história social do abandono de crianças: de Portugal ao Brasil - séculos XVIII-XX. São Paulo: Alameda; Belo Horizonte: PUC Minas. 2010.

VENÂNCIO, Renato Pinto.

Infância e pobreza no Rio de Janeiro, 1750-1808. História: Questões \& Debates, n.36, p.129-159. 2002.

VENÂNCIO, Renato Pinto.

Famílias abandonadas: assistência à criança de camadas populares no Rio de Janeiro e em Salvador - séculos XVIII e XIX. São Paulo: Papirus. 1999.

VIAZZO, Pier Paolo; BORTOLOTTO, Maria; ZANOTTO, Andrea.

Five centuries of foundling history in Florence: changing patterns of abandonment, care and mortality. In: Panter-Brick, Catherine; Smith, Malcolm T. (Ed.). Abandoned children. United Kingdom: Cambridge University Press. p.70-91. 2000.

VIVES, Juan Luis.

El socorro de los pobres/La comunicación de bienes. Estudio preliminar, traducción y notas de Luiz Frayle Delgado. Madrid: Tecnos. 2013.

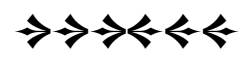

